

\title{
Research
}

\section{A comparative taxonomy of Australasian paramedic clinical practice guidelines}

Marc Colbeck CCP is a Critical Care Paramedic, Senior Lecturer, Course Coordinator and PhD candidate (medicine) ${ }^{1}$; Sonja Maria BClinPrac is a PhD candidate, Discipline Leader in Paramedical Sciences and Lecturer in Paramedicine ${ }^{2}$

\author{
Affiliations: \\ ${ }^{1}$ Australian Catholic University, Brisbane, Queensland \\ ${ }^{2}$ Charles Sturt University, Bathurst, New South Wales
}

\section{Abstract}

\section{Background}

There are 10 state-run ambulance services in Australia and New Zealand, all of which are members of the Council of Ambulance Authorities (CAA). These CAA services use nine unique sets of clinical practice guidelines (CPGs) to direct the care that their paramedics deliver to patients. Although there are many similarities in these guidelines there are also notable differences in both structure and content. This paper is a comparative analysis of these CAA CPGs that contrasts the differences in organisation and also discusses the similarities and differences between the various CPGs themselves. This comparison was done as a preparatory exercise for the creation of a set of national CPGs by Paramedics Australasia.

\section{Methods}

The complete set of CPGs were obtained and analysed. All CPGs intended for operational road paramedics were examined. These included extended care paramedic, retrieval and intensive/critical care paramedic CPGs, and first responders. The 10 tables of contents were synthesised into one document and then restructured into a unique taxonomy determined by consensus of the authors. The authors reviewed the taxonomy to ensure the organisation was consistent and logical. Each CPG was then reviewed to ensure that it was appropriately placed in the new taxonomy. The CAA CPGs were further examined for similarities and differences independently by each author according to a predefined list of characteristics.

\section{Results}

A new taxonomy for Australasian CPGs is presented with a discussion of various issues of interest that became apparent during the development of the taxonomy. This taxonomy can provide guidance in the creation of a unified set of CPGs that can be used as a reference for developers, educators, clinicians, researchers, managers and industry representatives interested in consulting and developing a clear statement of the scope and standards of Australasian paramedics. The comparative analysis could be of interest to developers of CAA CPGs, and others.

\section{Conclusion}

This paper presents a novel taxonomy, or scheme of classification, that incorporates all CAA CPGs in preparation for the development of a uniform set of Australasian CPGs, which will be of use to various individuals and organisations.

Keywords:

paramedic; Australasia; CPG; clinical practice guideline

Corresponding Author: Marc Colbeck, marc.colbeck@gmail.com 


\section{Introduction}

Paramedics are medical professionals trained to work in a range of settings providing care. The traditional role of paramedics is to work from ambulances that are dispatched to respond to sudden and acute life-threatening events (1). However, the role of paramedics is expanding to include long term care of the low-acuity out-of-hospital patient in the community, as well as the care of potential patients in remote sites such as mines and oil rigs, and of those undertaking prolonged transportation such as citizens being medically repatriated from other countries or those requiring high-acuity inter-facility transfers (2-5).

Unlike most health care workers, the culture of paramedicine includes an enforced adherence to strict clinical practice guidelines (CPGs). These CPGs are usually specific to the ambulance service or private organisation that deploys paramedics, and continued authority to practice with that organisation is usually dependent on compliance with these CPGs that, in effect, define the allowed scope and standards of paramedic practice.

There are 10 state-regulated ambulance services (paramedic provider services) in Australasia associated with the Council of Ambulance Authorities (CAA) (6). These services each produce CPGs that are intended to guide the practice of the paramedics they employ.

Paramedics in Australia are currently not registered under the Australian Health Practitioner Regulation Agency (AHPRA). This means that, unlike Ireland, the United Kingdom (UK), some Canadian and some Middle Eastern jurisdictions, Australian paramedics are not individually regulated medical professionals. This is set to change in 2018 at which time Australian paramedics will come under the jurisdiction of AHPRA as a fully self-regulated health profession. In New Zealand there is a push to similarly achieve paramedic selfregulation.

In preparation for this, Paramedics Australasia, which describes itself as 'the peak professional association representing practitioners who provide paramedic services to the community' (7) has undertaken to create a set of CPGs that would describe the scope and standards of practice for paramedicine across Australasia.

The purpose of the Paramedics Australasia CPGs (PA CPGs) is multifold:

- They will be a clear statement of the scope and standards of paramedic practice for organisations and individuals outside of the profession who wish deeper insight into paramedic abilities and standards

- They will help drive a research agenda intended to support the further development of the unique body of knowledge that defines and informs the practice of paramedicine

- They will act as a resource for paramedic academics to use in the education of paramedics at the undergraduate and graduate level as paramedic education continues to evolve beyond local vocational and skills-based training to a more national/international concept-based education

- Because they will be published in a peer-reviewed paramedic journal they will be able to be used as academic references for paramedicine students (unlike the current individual state ambulance service CPGs)

- They will be a resource for paramedics working under their own licence as to the most current and evidence-based standards of care

- They may assist to bridge gaps and differences in patient care that currently exist between services.

One of the authors of this paper (MC) has been tasked with leading the development of the PA CPGs. The second author (SM) has played an important role in the development of the project. Both are full time Australasian paramedic academics undertaking PhDs with a primary focus on paramedic CPGs. Both have also been involved in the writing of CPGs for CAA member services. Together they determined that an important first step in the project would be to develop a classification scheme - a taxonomy - for the PA CPGs so that there would be an overarching structure to guide their development. This paper describes the results of that work.

\section{Aims}

The first aim of this paper is to compare and contrast the existing CPGs of the 10 members of the CAA to look for similarities and differences in their structure and content. Specifically, the authors examined the following:

1. How many CPGs does each CAA service individually have?

2. Of those CPGs, how many apply directly to patient treatment (treatment-oriented CPGs) and how many relate to operational or medico-legal factors such as patient refusal, or when to request additional rescources etc. (nontreatment-oriented CPGs)?

3. How many of the treatment-oriented CPGs are referenced or describe external evidence to best practice?

4. Which CPGs are common to all CAA services?

5. Which CPGs do $80-90 \%$ of CAA member services have in common?

6. Which CPGs, if any, are unique to less than $30 \%$ of CAA member services?

The second aim is to create a novel taxonomy of CPGs that is inclusive of all of those currently found in the existing CPGs belonging to the 10 individual services associated with CAA. Taxonomy is the process of naming and classifying things such as animals and plants into groups within a larger system, according to their similarities and differences. 
Colbeck: Taxonomy of Australasian paramedicine clinical practice guidelines Australasian Journal of Paramedicine: 2018;15(2)

For our purposes, this taxonomy will group together common themes and categories of CPGs, bringing together those with a common functional and pragmatic purpose. This taxonomy will describe the subject areas and list the suggested titles for future CPGs. Subsequent work, to be undertaken after the publication of this paper, will focus on the writing of the individual CPGs and discovering the best research evidence to support them.

\section{Methods}

The following CPGs were obtained and form the basis of the analytical work in this paper. They are the most recent version of the CAA member services available.

1. Australian Capital Territory Ambulance Service Guidelines, 2017 (8)

2. New South Wales Ambulance 2016 Protocol and

Pharmacology (9) and Extended Care Paramedic

Operational Resources ${ }^{a}$

3. Ambulance Victoria Clinical Practice Guidelines, 2016.

Edition Version 1.1 (10)

4. Ambulance Tasmania Clinical Practice Guidelines, August 2015 (11)

5. Queensland Ambulance Service Clinical Practice Guidelines, 2017 (12)

6. South Australia Ambulance Service Paramedic Clinical Practice Guidelines, May 2015a

7. St John Ambulance Northern Territories Clinical Practice Guidelines Version 2.3, June 2013 (13)

8. St John Ambulance New Zealand Clinical Practice Guidelines. Comprehensive Edition, 2016-2018 (14)

9. St John Ambulance Western Australia Clinical Practice Guidelines, Version $24^{a}$
10.Wellington Free Ambulance Clinical Procedures and Guidelines. Comprehensive Edition 2016-2018 (15).

Where possible, only the full versions of the CPGs were used, the authors did not refer to pocketbooks or other summaries of the CPGs. The CPGs examined were current as of the date indicated for each reference. Additional items such as reference guides, pharmacology or skills sheets were not included.

Paramedics are authorised to work at different levels of clinical intensity and each level is given a unique title in the various CAA member services. Unfortunately, these titles and practice levels are not uniformly standardised among the CAA members. The authors therefore chose to use the titles defined by PA in their Role Descriptor document(1). The authors evaluated all CPGs which were intended for the level of practitioner described by the Role Descriptor document as: 'Retrieval Paramedics', 'Extended Care Paramedics', 'Community Paramedics', 'Intensive Care Paramedic', 'Paramedic', 'Basic Life Support Paramedic' or 'First Responder'(1).

In this study CPGs were evaluated to determine whether or not they were treatment oriented. The criterion used by the authors to determine if a CPG was 'treatment oriented' was as follows: Does the CPG contain instructions or recommendations in regards to a therapeutic procedure or administration of a medication? If so, it was considered to be 'treatment oriented'.

In order to ensure the accurateness of the analysis each author independently answered each of the first six questions listed in the section of this paper entitled 'Aims'. Results were then cross-validated and the final answers were determined through consensus. They then independently developed a sketch of a novel taxonomy of the CAA CPGs that were compared. Final results were determined through consensus.

aDirect communication: These are listed as 'direct communication' because they are not a published, openly available document. We obtained this directly from the organisation, so they have to be listed as a 'direct communication', and all references to direction communications are made as footmotes.

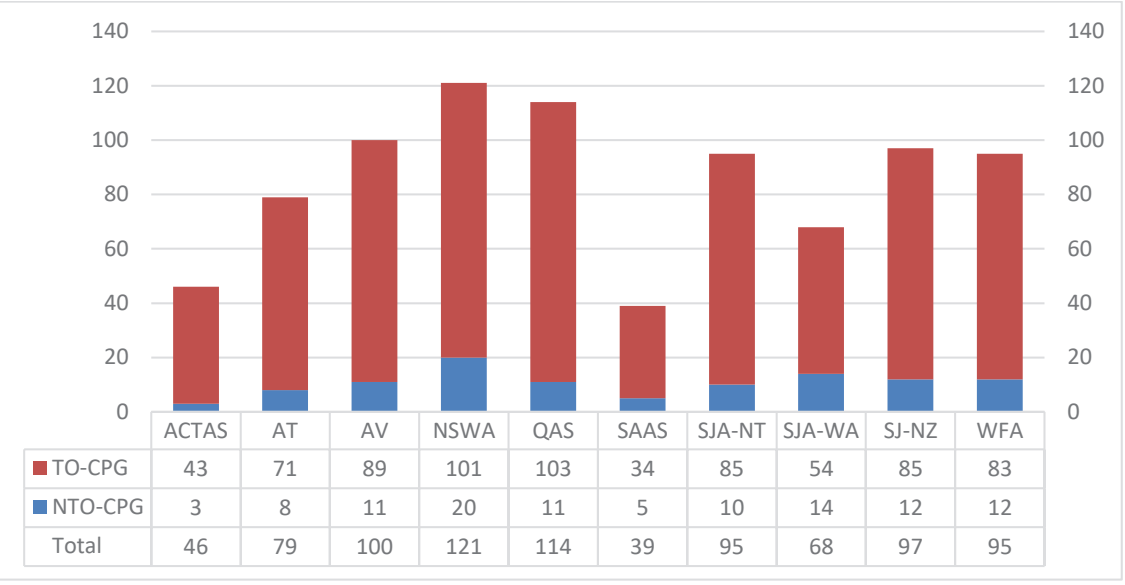

Figure 1. Comparison of non-treatment-oriented (NTO-CPG) and treatment-oriented (TO-CPG) CPGs 


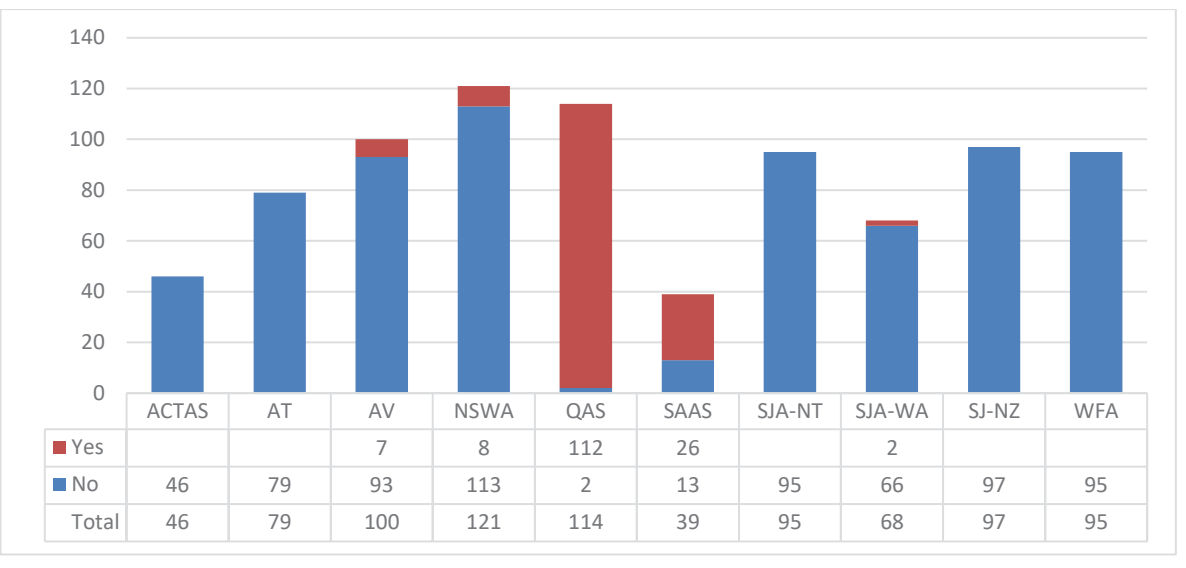

Figure 2. Referenced and unreferenced comparison of treatment-oriented CPGs

\section{Ethics}

The authors did not seek ethics approval as this was an evaluation of existing documents. The study did not involve human subjects, nor did it reveal personal data about human subjects.

\section{Results}

Figure 1 presents the total number of CPGs in each of the CAA ambulance services. Each service's CPGs are differentiated into those that are treatment oriented or non-treatment oriented according to the definition offered under 'Methods'.

The total number of treatment oriented CPGs in each of the CAA ambulance services is shown in Figure 2 and defines how many of these are referenced to sources of evidence external to the authoring agency.

Of the ten existing CAA member services with unique CPGs, all $(100 \%)$ of them had specific guidelines for the following 14 topics:

- Principles of general care: primary and secondary survey

- Cardiac: acute coronary syndrome

- Cardiac: dysrhythmias

- Circulatory: hypotension

- Medical: pancreatic

- Medical: pain

- Neurological: seizures

- Neurological: stroke

- Behavioural and mental health emergencies: agitated/ combative patient

- Trauma: spinal cord/neck

- Trauma: burns

- Toxicology: general

- Infectious: anaphylaxis

- Resuscitation: cardiac arrest - adult.
Of the 10 existing CAA member services with unique CPGs, eight or nine (80-90\%) of them had specific guidelines for the following 13 topics:

- Airway and breathing: asthma

- Airway and breathing: obstruction

- Cardiac: cardiogenic pulmonary oedema

- Medical: nausea and vomiting

- Neurological: autonomic dysreflexia

- Trauma: head/brain

- Trauma: limbs

- Environmental: temperature

- Environmental: dysbarism

- Infectious: sepsis

- Resuscitation: cardiac arrest-child and neonate

- Resuscitation: return of spontaneous circulation (ROSC)

- Resuscitation: role.

Of the 10 existing CAA member services with unique CPGs, less than three $(30 \%)$ had specific guidelines on the following 28 topics:

- Airway and breathing: hyperventilation

- Airway and breathing: pulmonary embolism

- Cardiac: acute aortic dissection

- Circulatory: vascular access

- Medical: adrenal

- Medical: dialysis

- Medical: non-traumatic back pain

- Neurological: spinal emergencies

- Behavioural and mental health emergencies: general mental health

- Trauma: pregnancy

- Trauma: fluid injection

- Environmental: 'hazmat'

- Toxicology: alcohol

- Toxicology: miscellaneous

- Infectious: minor allergy

- Infectious: viral haemorrhagic fever 
- Maternal: ectopic pregnancy

- Maternal: miscarriage/pre-term labour

- Maternal: placental abruption

- Maternal: placental praevia

- Maternal: uterine inversion

- Maternal: uterine rupture

- Resuscitation: peri-arrest

- Patient disposition: refusal

- Patient disposition: rejection

- Patient disposition: redirection

- Patient disposition: interfacility transfer

- Patient disposition: other.

On examination of the existing CAA member CPGs it became apparent that some were symptoms based (eg. 'shortness of breath) while others were diagnosis based (eg. 'asthma'). This heterogeneity of topics led to the taxonomy sometimes having more, or less, than the expected number of CPGs within each domain.

The following table is a novel taxonomy of the CPGs that was produced as a result of this study. The authors have added broad category headings and a numbering system for the sake of clarity. This new classification system allowed us to align and collate the ten existing sets of CAA member CPGs and to show the entire range of CAA member CPGs currently in use in Australasia. Writing a new set of actual CPGs will be the next step in this project. As of now, no unifying set of CPGs has been written for Paramedics Australasia, but we believe this taxonomy will provide a foundation for that work.

\section{Discussion}

The taxonomy presented above reflects an in-depth examination and synthesis of the current classifications of clinical practice guidelines for providing paramedic care across the CAA member ambulance services within Australia and New Zealand. To the best of our knowledge, this is the first time that the 10 individual sets of CAA member CPGs have been analysed and compared to build a comprehensive table of all types of guidelines used in the Australasian paramedic setting. This framework can now be used as a foundation for further Australasian CPG development.

In addition to being a foundation for further Australasian CPG development it is expected that this taxonomy may accomplish several other goals. It may be of interest to CAA services in finding commonality and bridging gaps and differences in their existing CPGs. It might be of use to universities that educate undergraduate paramedics as a guide to the content that must be covered in order to produce a competent graduate, ready to enter the workforce. Similarly, it may be of interest to the as yet unchosen organisation that will be tasked with accrediting paramedic undergraduate degrees in Australasia. It could be used by the Paramedic Board of Australia to help judge the equivalency of practice of foreign paramedics as well as the appropriateness of the clinical practice of soon-to-be licensed Australian paramedics. It may also be of use in helping to guide a research agenda to support the further development of the unique body of knowledge that defines and informs the practice of paramedicine.

The discrepancy in the number of evidence-based therapeutically-oriented CPGs across CAA member services that this paper revealed may also encourage the developers of these CPGs to adopt a more standardised and transparently evidence-based process for the development and presentation of their CPGs. There are internationally accepted, validated, and evidence-based, tools for the development of CPGs $(16,17)$ and if CPGs are developed using these tools there are distinct benefits to both patients and healthcare organisations (16). Using these tools to build CPGs discourages unwarranted variations in healthcare delivery which are recognised issues impacting the quality and safety of patient care $(17,18)$.

\section{Limitations of this study}

One limitation of this study is that the reasons for existing differences in CPGs across services was not explored. The researchers feel that it would be interesting to have gone into more detail in this area and to investigate what impact those differences might have, but they are aware that research in this area is currently being undertaken in other studies. Furthermore, the dataset used as the basis of this study the CPGs themselves - did not contain this information. It is not unreasonable to presume that the reasons for variation are likely due to historical and cultural factors that may have been subsequently influenced by convenience and serendipity. Examining these would require an entirely different methodology than the one used in this study.

Finally, this work was primarily meant as an initial structure upon which to build a comprehensive set of Australasian CPGs. It is likely that discussion which may be generated by this paper could deepen the authors' insight into the strengths of weakness of the taxonomy. The authors both encourage and welcome this discussion and feedback. Furthermore, in the course of subsequently developing the CPGs based on this taxonomy, a deeper understanding of the interrelationships and overlaps between the proposed CPGs could be revealed. For both of these reasons, it would not be surprising to the authors if the final index of the proposed national CPGs was not entirely the same as the taxonomy presented in this paper.

\section{Conclusion}

This paper presents a novel taxonomy that incorporates all CAA CPGs in preparation for the development of a uniform set of Australasian CPGs which will be of use to various individuals and organisations. The next step in this project will be the development of the proposed individual PA CPGs themselves. 


\section{Conflict of interest}

The authors declare no competing interests. The authors of this paper have completed the ICMJE conflict of Interest statement.

\section{Acknowledgement}

The authors acknowledge the support given by Paramedics Australasia in the initiation of this project, and the support of Karen Lillywhite, of Flinders University, for her assistance in the advanced formatting of the Excel spreadsheet used to organize the work done in this paper.

\section{References}

1. Paramedics Australasia. Paramedicine role descriptors 2012. Available at: https://paramedics.org/wp-content/ uploads/2016/09/PRD_211212_WEBONLY.pdf

2. Blacker $\mathrm{N}$, Pearson L, Walker T, editors. Redesigning paramedic models of care to meet rural and remote community needs. 10th National Rural Health Conference; 2009.

3. O'Meara PF, Tourle V, Stirling C, Walker J, Pedler D. Extending the paramedic role in rural Australia: a story of flexibility and innovation. Rural Remote Health 2012;12:112.

4. Stirling C, O'Meara P, Pedler D, Tourle V, Walker JH. Engaging rural communities in health care through a paramedic expanded scope of practice. ibid. 2007;7:1-9.

5. Bigham BL, Kennedy SM, Drennan I, Morrison LJ. Expanding paramedic scope of practice in the community: a systematic review of the literature. Prehosp Emerg Care 2013;17:361-72.

6. Council of Ambulance Authorities. About the CAA 2017. Available at: www.caa.net.au/about-us [Accessed 8 March 2018].

7. Paramedics Australasia. About Paramedics Australasia 2017. Available at: www.paramedics.org/about/ [Accessed 8 March 2018].

8. ACT Ambulance Service. Clinical management guidelines 2017. Available at: http://esa.act.gov.au/actas/about-us/ clinical-management-guidelines/ [Accessed 8 March 2018].

9. NSW Ambulance. Ambulance protocols and pharmacology 2016. Available at: http://ciap.hcn.com.au/www.ciap.health. nsw.gov.au/specialties/cda.html [Accessed 8 March 2018].

10.Ambulance Victoria. Clinical practice guidelines for MICA and ambulance paramedics. Melbourne, Victoria; 2017. Available at: http://s3-ap-southeast-2.amazonaws.com/prod. assets.ambulance.vic.gov.au/wp-content/uploads/2016/07/ CPG-2016-Edition-Vs.1.1web-reducedsize-flattenedsecure.pdf [Accessed 8 March 2018].

11. Ambulance Tasmania. Clinical practice guidelines for Ambulance Tasmania 2015. Available at: www.dhhs.tas. gov.au/ambulance/clinical_services/medical_protocols/ paramedic_protocols [Accessed 9 March 2018].

12. Queensland Ambulance Service. QAS clinical practice manual. Kedron Park, Brisbane: Queensland Government; 2017. Available at: www.ambulance.qld.gov.au/CPGtable. html [Accessed 8 March 2018].

13.St John Ambulance NT. Clinical practice manual version 2.3, 2013. Available at: www.stjohnnt.org.au/img/documents/ clinical-manuals/CPG-HV23June2013.pdf [Accessed 8 March 2018].

14.St John. Clinical procedures and guidelines: comprehensive edition 2016-2018. Available at: www.rgpn.org.nz/Network/ media/documents/St\%20John\%20CPGs\%202016-18/ St-John-CPGs,-comprehensive-edition,-2016-2018.pdf [Accessed 8 March 2018].

15.Wellington Free Ambulance. Clinical procedures and guidelines: comprehensive edition 2016-2018. Available at: www.wfa.org.nz/file/931/WFACPG_Comprehensive_ LQ170228.pdf [Accessed 8 March 2018].

16. Burgers JS, Grol RPTM, Zaat JOM, Spies TH, Van Der Bij AK, Mokkink HGA. Characteristics of effective clinical guidelines for general practice. Br J Gen Pract 2003;53:159.

17. Woolf SH, Grol R, Hutchinson A, Eccles M, Grimshaw $J$. Potential benefits, limitations, and harms of clinical guidelines. BMJ 1999;318:527-30.

18.Agree Collaboration. Development and validation of an international appraisal instrument for assessing the quality of clinical practice guidelines: the AGREE Project. Qual Saf Health Care 2003;12:18-23. 


\begin{tabular}{|c|c|c|c|c|c|c|c|c|c|c|c|c|c|c|c|c|c|c|}
\hline 岕 & ন্ & ㅇ & 0 & $\simeq$ & ما & 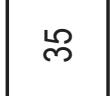 & $\stackrel{m}{\square}$ & $E$ & ما & $\sim$ & $\sim$ & $\sim$ & $\nabla$ & $\nabla$ & ㅇ & 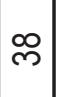 & $\mp$ & - \\
\hline 芯 & $m$ & - & $\sim$ & $m$ & - & $r$ & $\sim$ & - & 0 & - & 0 & 0 & 0 & - & $\nabla$ & | & $\sim$ & 0 \\
\hline 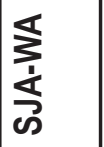 & $\sim$ & $\sim$ & 0 & $\sim$ & - & $\nabla$ & 0 & - & 0 & - & 0 & 0 & - & 0 & - & $\nabla$ & $\sim$ & 0 \\
\hline $\begin{array}{l}\mathbf{N} \\
\dot{j} \\
\mathbf{m}\end{array}$ & $\nabla$ & $m$ & $\sim$ & $m$ & - & 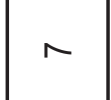 & $\sim$ & - & 0 & - & 0 & 0 & 0 & - & $\nabla$ & 10 & $\sim$ & 0 \\
\hline 妾 & - & 0 & 0 & 0 & 0 & 0 & $r$ & - & - & - & - & - & - & 0 & - & $m$ & - & 0 \\
\hline 悉 & $\sim$ & 0 & 0 & 0 & 0 & 0 & - & $\sim$ & - & 0 & 0 & 0 & 0 & 0 & $\sim$ & $m$ & 0 & 0 \\
\hline$\frac{\infty}{8}$ & $\sim$ & 0 & - & $\sim$ & 0 & 0 & $r$ & - & $\sim$ & - & $r$ & - & - & - & - & $m$ & - & - \\
\hline$\gtreqless$ & - & $\wedge$ & 0 & 0 & - & 0 & $\sim$ & - & 0 & - & 0 & 0 & 0 & 0 & $\sim$ & | 1 & - & 0 \\
\hline 这 & - & 10 & 0 & 0 & 0 & 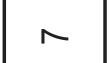 & $\sim$ & - & 0 & 0 & 0 & 0 & 0 & 0 & - & 10 & - & 0 \\
\hline$\frac{5}{\frac{\pi}{2}}$ & $m$ & $\sim$ & - & $\sim$ & $\leftarrow$ & 0 & - & $\sim$ & $\leftarrow$ & - & 0 & 0 & - & - & m & $\sim$ & $\leftarrow$ & 0 \\
\hline 电 & - & 0 & 0 & 0 & 0 & $\checkmark$ & - & 0 & 0 & 0 & 0 & 0 & 0 & 0 & - & $m$ & 0 & 0 \\
\hline 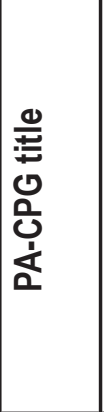 & 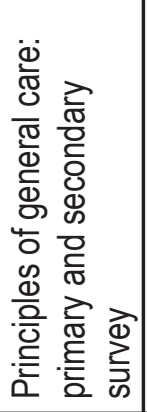 & 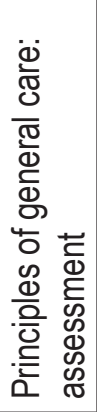 & 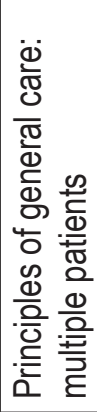 & 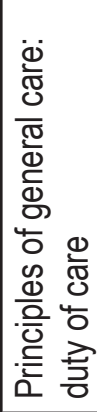 & 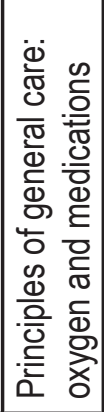 & 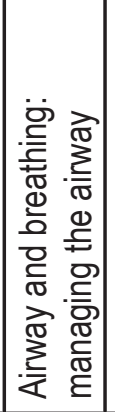 & 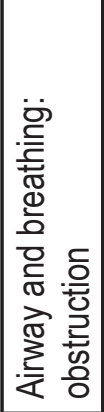 & 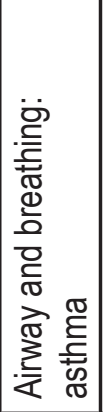 & 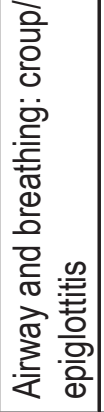 & 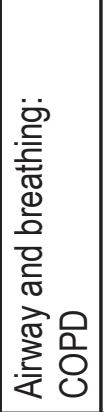 & 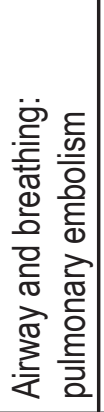 & 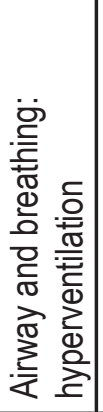 & 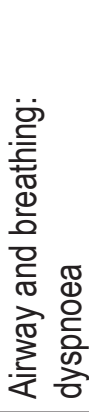 & 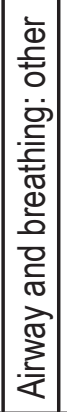 & 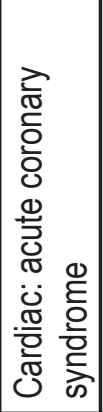 & 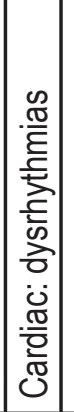 & 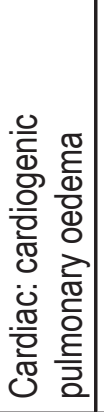 & 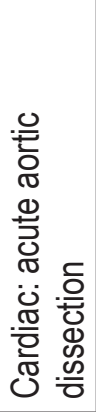 \\
\hline 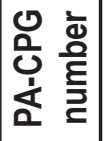 & 훈 & 足 & 产 & 定 & $\stackrel{2}{2}$ & $\bar{\varnothing}$ & ఇి & లి & 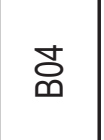 & 요 & ஜ & 요 & ○్ & 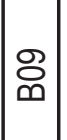 & ర్ర & $\begin{array}{l}- \\
0 \\
0\end{array}$ & ஜి & ర্ঠ \\
\hline 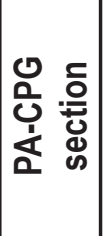 & 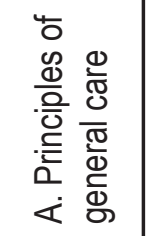 & & & & & 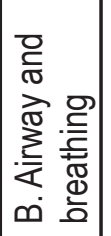 & & & & & & & & & $\begin{array}{l}\frac{.}{\pi} \\
\frac{.0}{0} \\
\frac{\pi}{\pi} \\
0 \\
0\end{array}$ & & & \\
\hline
\end{tabular}




\begin{tabular}{|c|c|c|c|c|c|c|c|c|c|c|c|c|c|c|c|c|c|c|c|c|}
\hline$\frac{1}{\stackrel{5}{\circ}}$ & $\bar{m}$ & 0 & $\sim$ & $\stackrel{ㅁ}{\square}$ & $\sim$ & $\nabla$ & m) & $\lambda$ & $\sim$ & $\mp$ & $\cong$ & ( & $\simeq$ & $\cong$ & $\sigma$ & 100 & - & $\cong$ & $m$ & ما \\
\hline 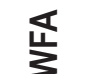 & 10 & - & - & $\sim$ & 0 & 0 & 0 & - & - & - & - & $\sim$ & - & $\sim$ & - & - & 0 & $\leftarrow$ & 0 & $\leftarrow$ \\
\hline 离 & $m$ & - & 0 & $\sim$ & 0 & 0 & - & 0 & 0 & 0 & - & $\sim$ & -1 & - & 0 & 0 & 0 & - & 0 & 0 \\
\hline 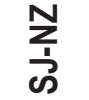 & $\nabla$ & - & - & $\sim$ & 0 & 0 & 0 & - & $\leftarrow$ & $r$ & - & $\sim$ & -1 & $\sim$ & - & - & 0 & - & 0 & $\leftarrow$ \\
\hline 卓 & $\sim$ & 0 & 0 & $\sim$ & 0 & - & 0 & - & 0 & $r$ & - & $\leftarrow$ & -1 & - & - & - & 0 & - & 0 & $r$ \\
\hline 交 & $\sim$ & 0 & 0 & - & 0 & 0 & 0 & 0 & 0 & $r$ & - & 0 & -1 & - & - & 0 & 0 & - & 0 & 0 \\
\hline \&) & $\sim$ & - & 0 & $\sim$ & - & - & 0 & - & 0 & - & - & - & - & - & $r$ & - & - & $\sim$ & 0 & - \\
\hline$\gtreqless$ & $\nabla$ & 0 & 0 & $\sim$ & 0 & 0 & 0 & 0 & 0 & $\sim$ & $\sim$ & 0 & $\sim$ & - & - & - & 0 & $r$ & - & 0 \\
\hline を & $\theta$ & 0 & 0 & $\sim$ & 0 & 0 & 0 & 0 & 0 & $\sim$ & $\sim$ & 0 & $\sim$ & - & $r$ & 0 & 0 & - & - & 0 \\
\hline$\frac{5}{\infty}$ & $\nabla$ & $\sim$ & 0 & m & - & - & - & $\sim$ & 0 & - & - & 0 & -1 & - & - & 0 & 0 & - & - & - \\
\hline 象 & - & 0 & 0 & - & 0 & - & - & - & 0 & - & - & - & - & - & - & 0 & 0 & $\sim$ & 0 & 0 \\
\hline 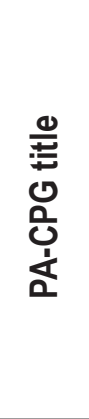 & 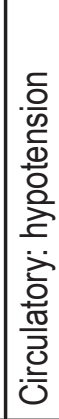 & 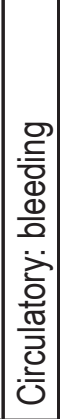 & 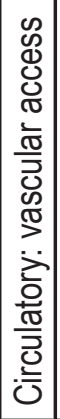 & 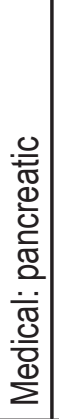 & 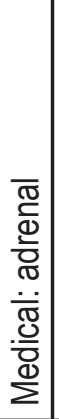 & 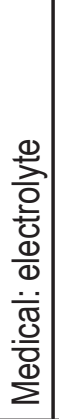 & 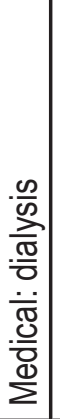 & 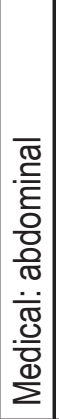 & 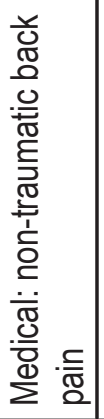 & 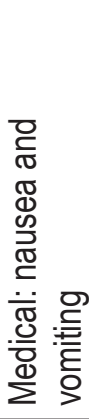 & 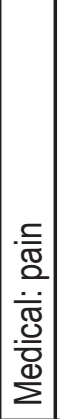 & 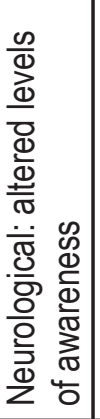 & 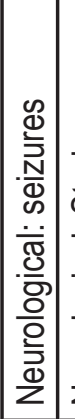 & 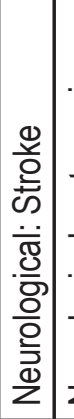 & 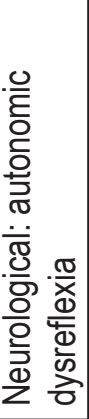 & 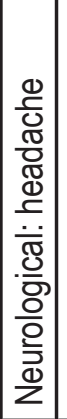 & 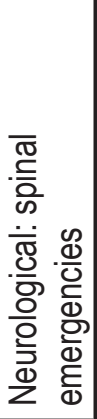 & 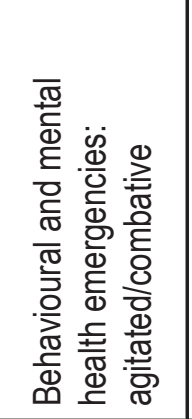 & 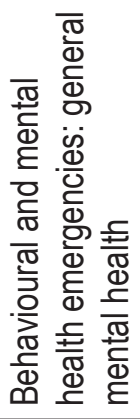 & 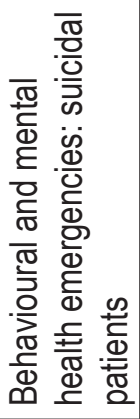 \\
\hline 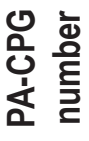 & চ் & 令 & ஜ̊̊̆ & 히 & 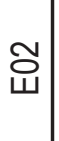 & రి & 壱 & 点 & 요 & 오 & 离 & 훈 & 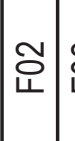 & 우 & ষ্ণ & 总 & 8 & চ্ণ & ర్ & ర్రి \\
\hline 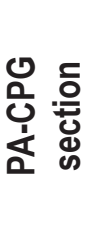 & 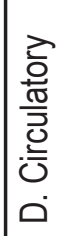 & & & 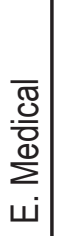 & & & & & & & & 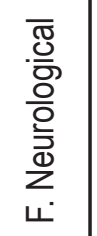 & & & & & & 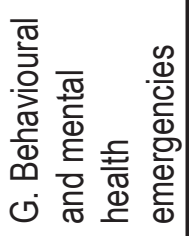 & & \\
\hline
\end{tabular}




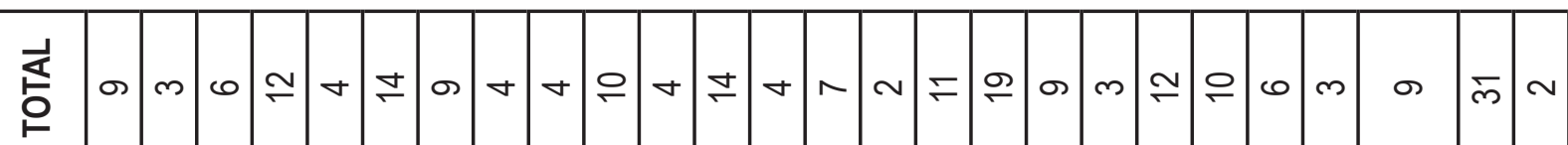

乔 00 -

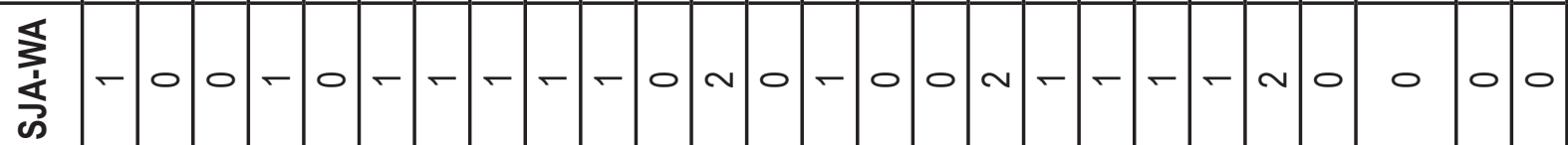

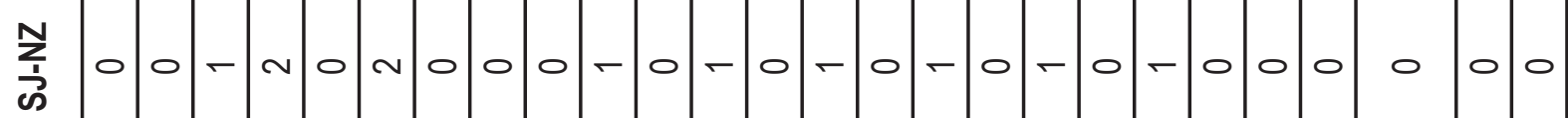

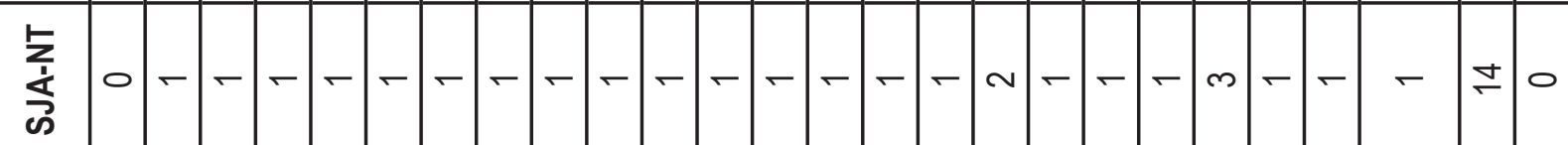

क

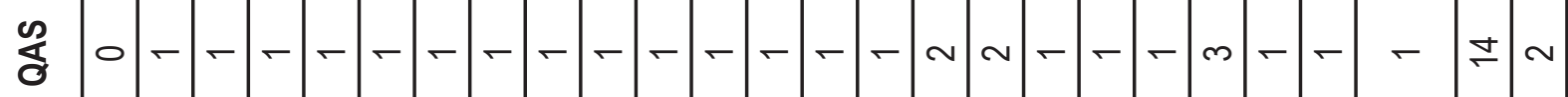

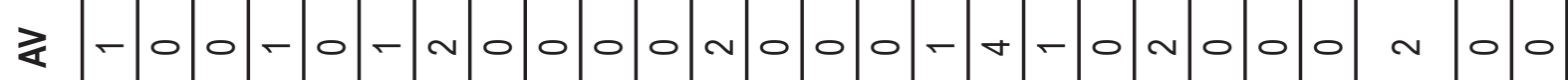

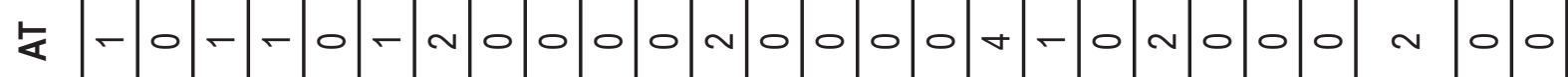

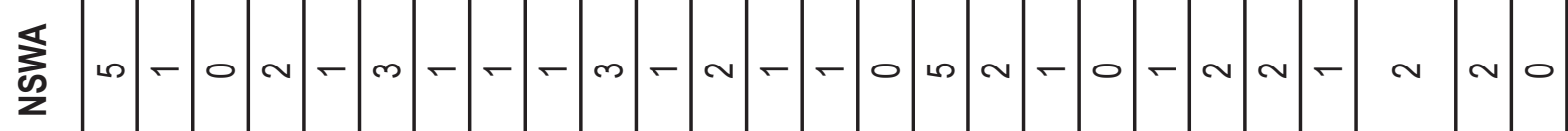

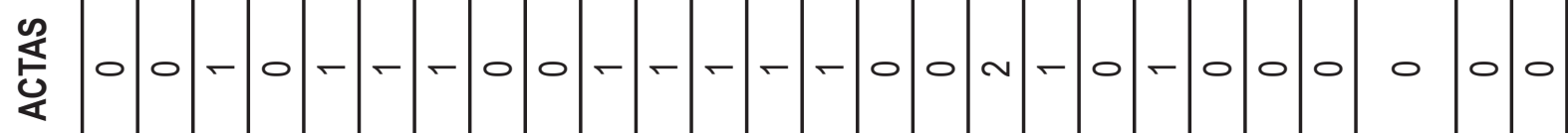

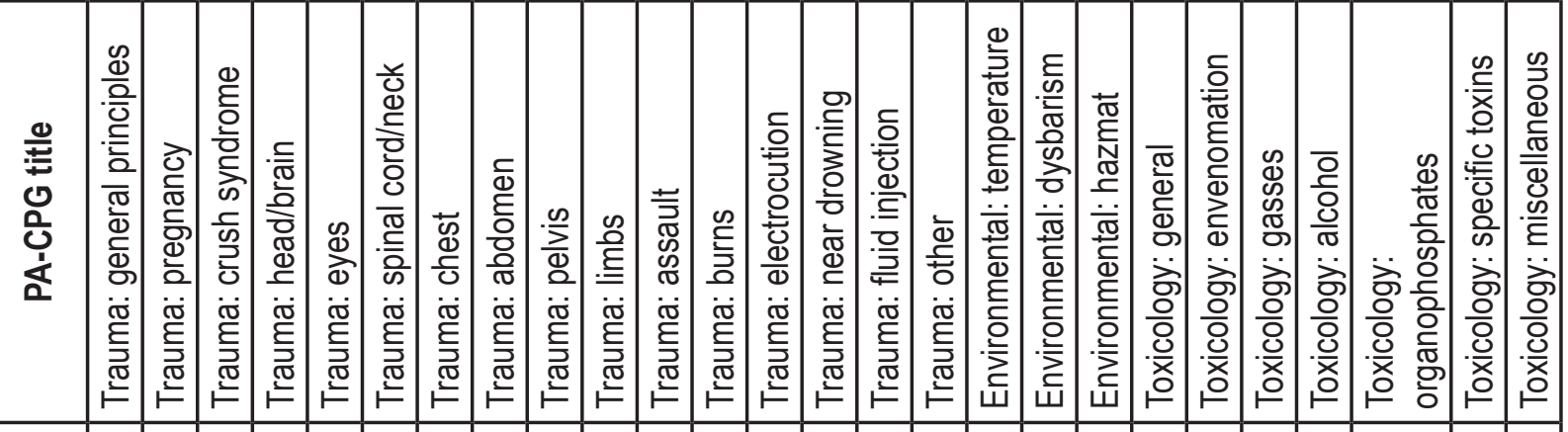

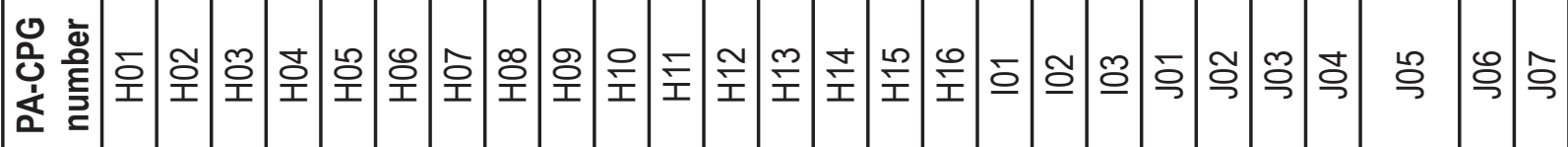

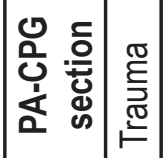

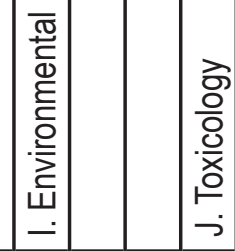




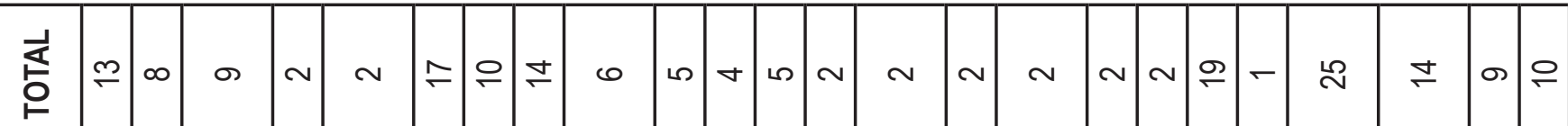

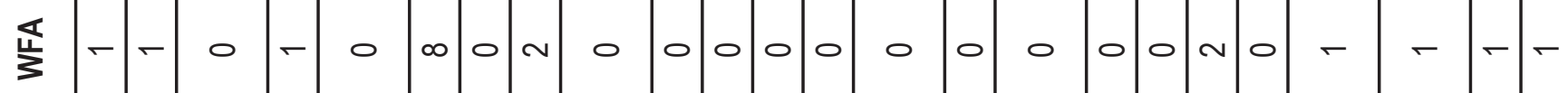

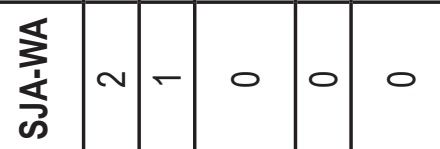

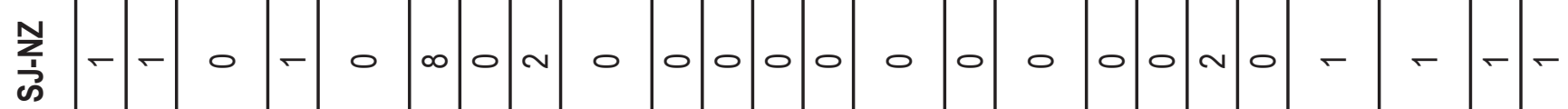

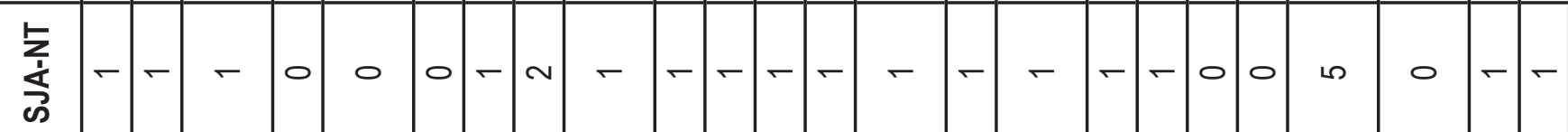

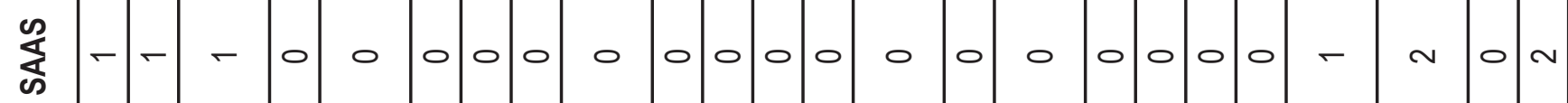

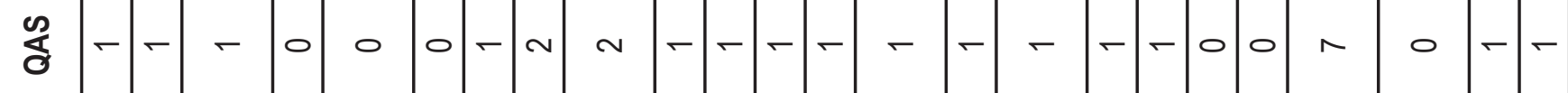

$\varangle$
$\varangle$

造 $N$ N

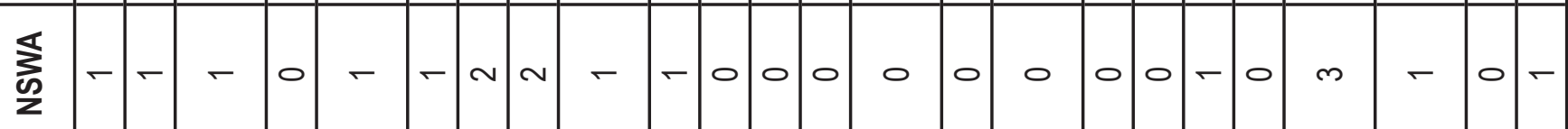

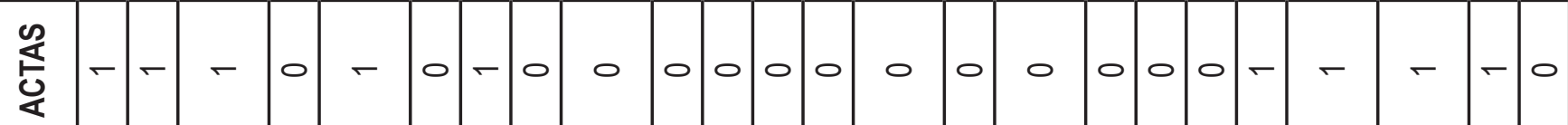

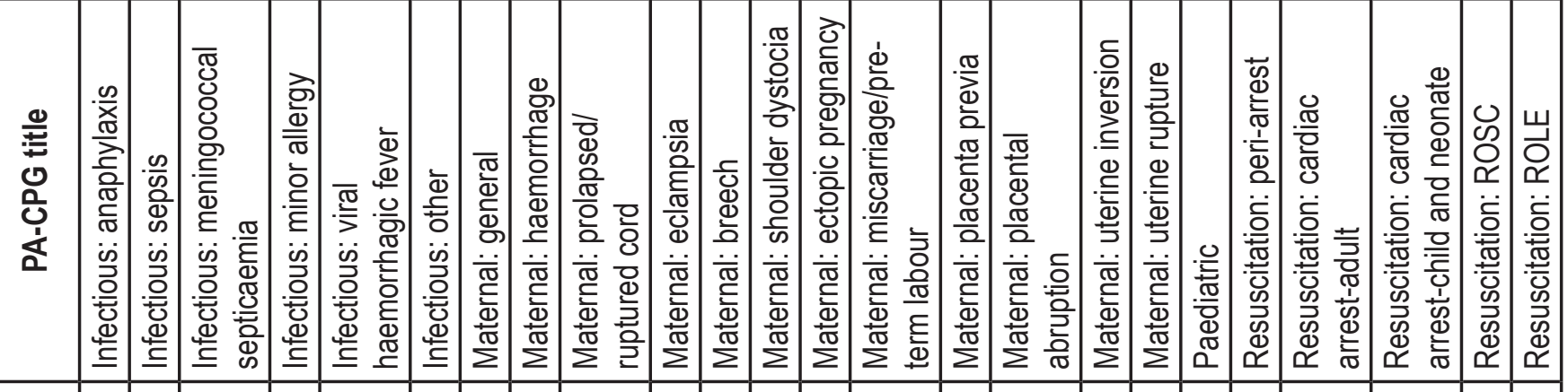

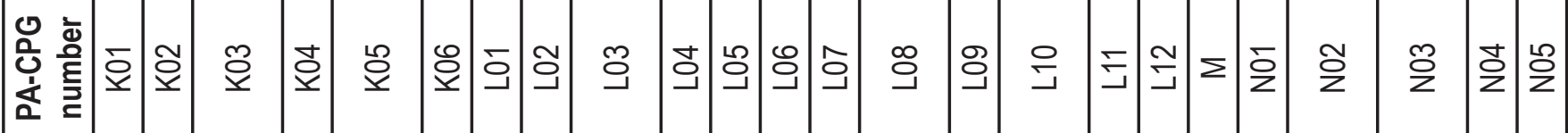

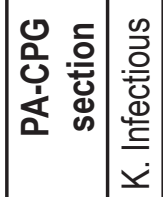


Colbeck: Taxonomy of Australasian paramedicine clinical practice guidelines Australasian Journal of Paramedicine: 2018;15(2)

\begin{tabular}{|c|c|c|c|c|c|c|c|c|}
\hline 崖 & 0 & $\stackrel{\sim}{\sim}$ & $m$ & \pm & m & - & $m$ & - \\
\hline 芯 & - & $r$ & 0 & $\sim$ & 0 & 0 & 0 & 0 \\
\hline 紊 & 0 & 0 & 0 & $m$ & 0 & 0 & - & 0 \\
\hline 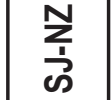 & - & 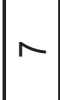 & 0 & $\sim$ & 0 & 0 & 0 & 0 \\
\hline 桌 & - & 0 & $\sigma$ & - & 0 & 0 & $\leftarrow$ & 0 \\
\hline$\sum_{\infty}^{\infty}$ & 0 & 0 & 0 & 0 & -1 & 0 & 0 & 0 \\
\hline \&) & - & $\sim$ & 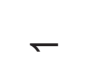 & - & 0 & - & 0 & 0 \\
\hline$\gtreqless$ & 0 & 0 & 0 & 으 & 0 & 0 & 0 & 0 \\
\hline 尗 & 0 & 0 & 0 & 0 & 0 & 0 & 0 & 0 \\
\hline 齐 & $\sim$ & 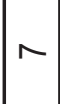 & - & 10 & $\sim$ & 0 & $\leftarrow$ & - \\
\hline$\frac{0}{E}$ & 0 & - & 0 & 0 & 0 & 0 & 0 & 0 \\
\hline 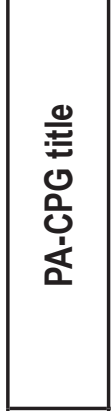 & 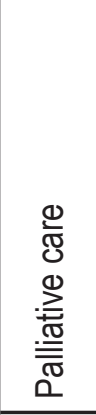 & \begin{tabular}{|l}
$\bar{\Phi}$ \\
Фे \\
ठ
\end{tabular} & 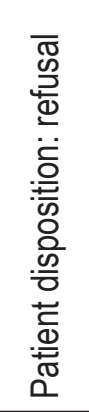 & 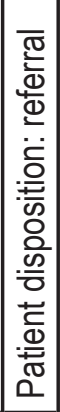 & 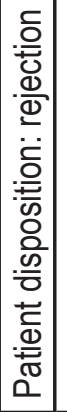 & 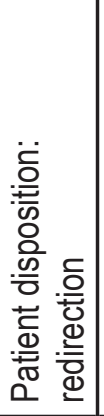 & 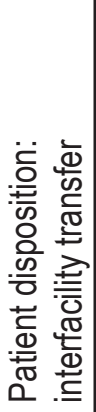 & 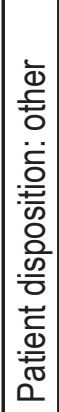 \\
\hline 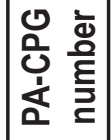 & 0 & a & $\overline{8}$ & ชి & రి & षे & 용 & O̊ \\
\hline 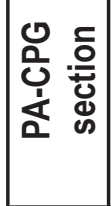 & 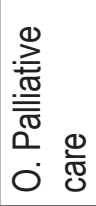 & \begin{tabular}{|l}
$\bar{\Phi}$ \\
$\stackrel{ \pm}{ \pm}$ \\
0 \\
0.
\end{tabular} & 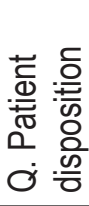 & & & & & \\
\hline
\end{tabular}

